\title{
Distance sampling as an effective method for monitoring feral pigeon (Columba livia f. domestica) urban populations
}

\author{
Dimitri Giunchi • Valentina Gaggini • \\ N. Emilio Baldaccini
}

(C) Springer Science + Business Media, LLC 2007

\begin{abstract}
Current methods for estimating feral pigeon (Columba livia) population size and for monitoring population trends are mainly based on indices, which according to the current literature on wildlife census methods often produce biased results. Distance Sampling techniques have never been used in this context, even though they could theoretically produce absolute abundance estimates at relatively low costs. The aim of this paper was to investigate the performance of Distance Sampling to census feral pigeons, and to compare these results with those obtained by using Quadrate Counts, a widespread method for monitoring these birds. Surveys were performed in Pisa (Italy) in two different periods of the year 2004 (end of January-beginning of February, and November), which correspond to a minimum (January-February) and a maximum (November) numbers for pigeon populations. We conducted 40 line transects each about $250 \mathrm{~m}$ long for Distance Sampling, and $40250 \times 250 \mathrm{~m}$ cells for Quadrate Counts. In both cases, sampling units were randomized in a stratified design. In contrast to Quadrate Counts, Distance Sampling detected the predicted increase of abundance from January-February to November with an acceptable precision and no increase of costs per survey. Even though the possible biases (due to the not rigorously random distribution of transects and to the spiked nature of collected distances) should be further investigated, results suggest that Distance Sampling is a viable and efficient alternative to the traditional methods used to estimate feral pigeons population size and to monitor trends.
\end{abstract}

Keywords Feral pigeons · Census technique · Distance sampling · Quadrate counts

\section{Introduction}

Feral pigeon (Columba livia f. domestica) populations have shown large numerical 35 increases both in Europe and in North America following World War II (see Johnston and 36 Janiga 1995 for a review). These large numbers have given rise to the development of a

D. Giunchi $(\triangle) \cdot$ V. Gaggini $\cdot$ N. E. Baldaccini

Dipartimento di Biologia, Università di Pisa, Via A. Volta 6, I-56126 Pisa, Italy

e-mail: dgiunchi@biologia.unipi.it 
considerable number of pest control techniques for this species (see Johnston and Janiga 1995 for a review), while, in comparison, research aimed to develop unbiased methods for estimating pigeon population size has aroused far less interest. Unbiased estimates of pest abundance are essential for: (1) the assessment of pest population size to justify control; (2) the choice of appropriate control methods; (3) a plausible estimate of the costs for control; and (4) an overall estimate the effectiveness of control. Pigeons counts are intrinsically difficult and often costly because of the characteristics of urban environments (e.g., complex structure and poor visibility), and of the pigeons themselves (e.g., clustered distribution, high density, high vagility; see Johnston and Janiga 1995; Jokimäki and Suhonen 1998; Buijs and Van Wijnen 2001; Rose et al. 2006; Soldatini et al. 2006, and references therein). This often has led several authors to disregard methods whose estimators adjust for imperfect detectability (e.g., capture-recapture) and to adopt a number of ad hoc and uncalibrated indexes of population abundance, such as counts of naturally occurring flocks (e.g., Buijs and Van Wijnen 2001), counts of birds attracted with food (e.g., Sacchi et al. 2002), or uncorrected transect counts (e.g., Bursi et al. 2001). Population indexes are widely used in wildlife monitoring programs because they are less costly. There is, however, an increasing concern about their utilization (see Pollock et al. 2002; Rosenstock et al. 2002; Thompson 2002; Anderson 2003), because their critical assumption - the proportionality between index and true population density-is usually violated. A step in the direction to an unbiased estimate of feral pigeons abundance is represented by Quadrate Counts (Uribe et al. 1984; Senar and Sol 1991; Senar 1996), i.e. pigeon counts carried out by walking along a random sample of square, non-overlapping sampling units into which the study area is divided. Even though the choice of sampling units could be based on a rigorous sampling protocol, Quadrate Counts always produce a biased estimate of the population size, since they do not take into account the birds' detectability. This bias could be adjusted by using an appropriate correction factor estimated by means of a sort of double sampling procedure (Cochran 1977; Bart and Earnst 2002), i.e. by surveying a subsample of units using an "intensive" survey method such as a mark-resight procedure (Senar and Sol 1991; Senar 1996). Even though this method can produce accurate results, it is costly and requires a noticeable number of marked individuals (often $>100$ ). The few studies which estimated correction factor using this procedure produced, however, quite consistent results (Senar and Sol 1991; Barbieri and De Andreis 1991; Sacchi et al. 2002), leading Senar (1996) to propose to multiply the results of Quadrate Counts by 3.5, i.e. a reasonable average figure of the correction factors reported in the literature. The outcome of this "simplified" procedure should be considered a very rough indication of the magnitude of actual population size, since it is reasonable to hypothesize that the number of birds that will pass undetected in different surveys is variable, depending on characteristics of the study area and on behavior of the pigeons themselves [e.g., daily schedule of foraging activity (Lefebvre and Giraldeau 1984; Rose et al. 2006; Soldatini et al. 2006); breeding activity (Johnston and Janiga 1995); etc.]. Moreover, the precision of the estimate is biased, since variability of the sampling estimate of correction factor is usually not considered in calculations.

As far as we know, Distance Sampling (Buckland et al. 2001) has never been used on feral pigeons, even though it should theoretically produce accurate estimates of population size at lower costs than other unbiased survey techniques, such as capture-recapture. Despite the potential value of this method, problems concerning 1) the validity of statistical assumptions underlying line transect methodology (see below), and 2) the statistical background needed in order to analyze collected data have probably represented an obstacle 
Urban Ecosyst

to its application. This paper investigates the performance of Distance Sampling in this context and compares results of this method with those obtained using Quadrate Counts.

\section{Methods}

Study area and general sampling method

The study was conducted in 2004 considering most of the built-up area of Pisa $\left(43^{\circ} 43^{\prime} \mathrm{N}\right.$, $10^{\circ} 24^{\prime}$ E, 30 m a.s.1., 90000 inhabitants). Several studies document that the distribution of feral pigeons is clumped. Indeed, even though production and survivorship tend to be lowest in densest urban areas (see Haag 1990, 1991) as recorded for other synantropic bird species (see e.g. Marzluff et al. 2001), pigeon density is usually higher in historical town centres, which are characterized by higher number of suitable nesting sites, higher human population density, and a relatively constant food availability (e.g. organic waste, public feeding; see Johnston and Janiga 1995; Jokimäki and Suhonen 1998; Buijs and Van Wijnen 2001; Sacchi et al. 2002). In this situation, the use of a stratified random sampling is recommended, because it can significantly increase the precision of the estimate (Senar and Sol 1991; Senar 1996), even if it is based only on little prior information (Thompson et al. 1998; Buckland et al. 2001). The study area was thus subdivided into two strata (Fig. 1) on the basis of environmental features of built-up areas, especially with regard to density and architectural characteristics of buildings, and of previous information on the distribution of feral pigeons in Pisa (Baldaccini et al., unpublished data). The first stratum (stratum 1= $2.6 \mathrm{~km}^{2}$ ) extended over the historic centre of the city and is characterized by a high density of old buildings constructed before World War II (and a large part of them during the Medieval Age). The second stratum included the less densely built peripheral area (stratum $2=7.7 \mathrm{~km}^{2}$ ) characterized by a large percentage of relatively more recent and architecturally more variable constructions than stratum 1 .

To test the power of these two census methods in detecting changes in size of an unmanaged pigeon population, surveys were replicated during two different periods (Thompson et al. 1998): end of January-beginning of February (hereafter "January") and November. Both periods were presumably characterized by low reproductive activity by feral pigeons, as suggested by both personal observations and published data (Johnston and Janiga 1995; Giunchi et al. 2007). This means that the number of birds virtually undetectable when attending eggs or squabs should have been relatively low. Considering the local climate and reported data on population dynamics of feral pigeons (Johnston and Janiga 1995), January and November surveys sampled the population in two rather different phases of its annual cycle. January counts were carried out in the coldest period of the year just before the beginning of the breeding season, indicated by the large number of birds observed in courtship behaviour. The November survey was performed after the breeding season just before wintertime, when population size is expected to be at its annual peak.

Surveys were carried out by the same observer. Birds were counted within $2 \mathrm{~h}$ after sunup. During this time period most pigeons remain within the city, usually near nesting or roosting sites, possibly searching for food nearby, while the number of birds leaving the city for feeding grounds in agricultural areas is very low (pers. obs., Soldatini et al. 2006 and references therein). This counting strategy should alleviate any eventual bias due to large scale movements even though it has the drawback of a potential reduction of the visibility of pigeons because of their relatively low mobility during the first daylight hours. 
Fig. 1 Map of the study area and of the two strata used during sampling procedures (a). Selected sampling units used in Distance Sampling (black segments) and Quadrate Counts (hatched squares) (b)
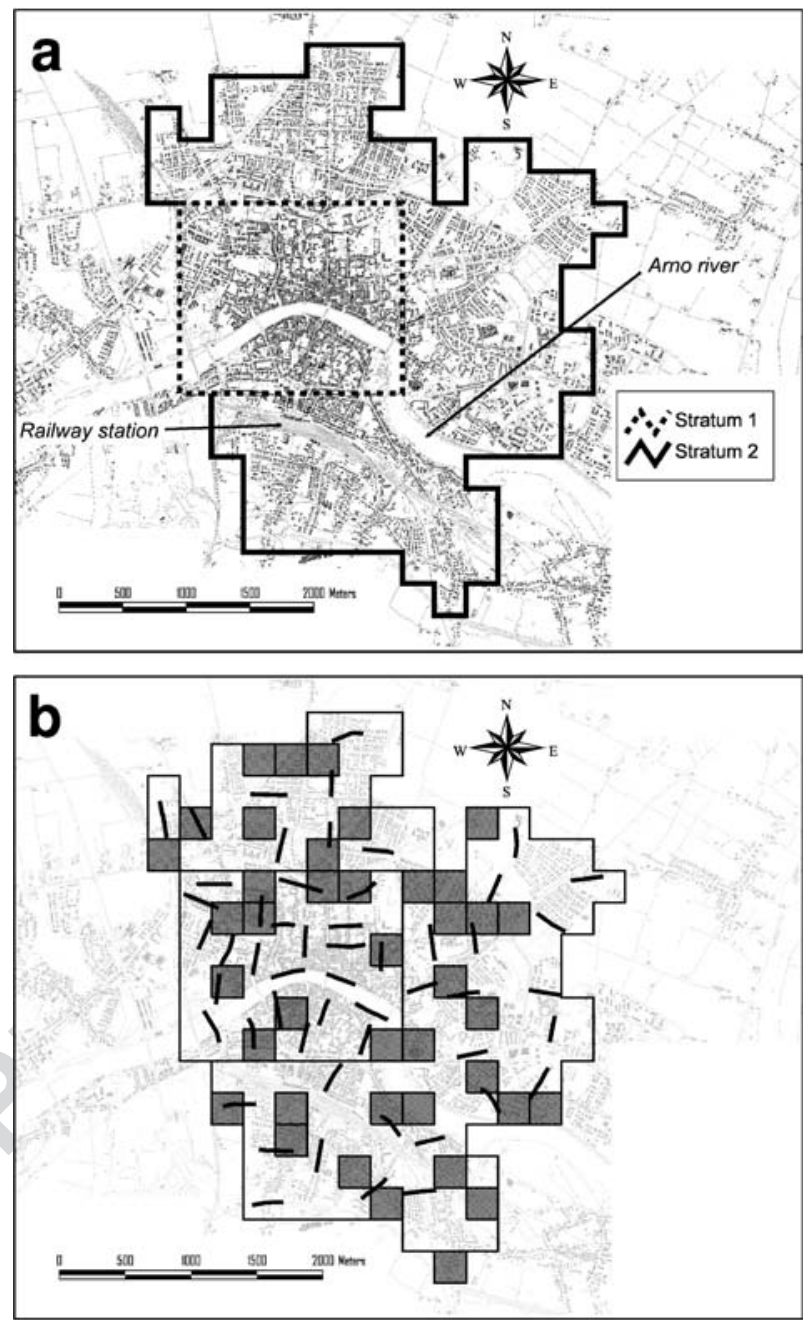

Distance sampling

40 line transects were allocated proportionally to each stratum (stratum 1 had 10 transects, stratum 2 had 30 transects; Fig. 1). Position and orientation of these transects were randomly determined by means of the extension "DNR random sampling tools 1.1" of GIS ARCVIEW 3.2, considering $300 \mathrm{~m}$ as transect length and $150 \mathrm{~m}$ as minimum transect spacing in order to reduce the likelihood of double counts. Transects created by the software were then adapted to the urban road network using a 1:2000 map of the study area (Regione Toscana, Carta Tecnica Regionale, available at http://www.rete.toscana.it/sett/ territorio/carto/cartopage/index.htm) by considering the best overlapping linear path. In order to avoid very short trails, we also took into account transects with moderate curvature, as Distance Sampling should apply also in these cases (Buckland et al. 2001). Due to the convoluted road network of the city, length of transects was less than $300 \mathrm{~m}$ (mean $\pm \mathrm{SD}$; 
$261 \pm 31 \mathrm{~m}$ ), but total sampling effort still remained roughly proportional to the stratum area (total transects length: stratum $1=2739 \mathrm{~m}$, stratum $2=7697 \mathrm{~m}$ ).

We walked transects at a slow pace, paying attention to all birds seen or heard. To increase the probability of detection of pigeons resting on buildings roofs or façades in the vicinity of the line, the observer followed a zigzag path by alternating very short paths on left and right pavements and occasionally looked behind in search of birds passed undetected. The position of detected birds was accurately determined $( \pm 2 \mathrm{~m})$ on the map of the study area. As for surveys of birds in forest (see Buckland et al. 2001), the location of pigeons perching on buildings was mapped on a point on the ground vertically below the birds themselves. Due to the flocking behaviour of feral pigeons, birds were often detected as groups. These groups were treated as single locations placed on the gravity centre of the groups themselves, since this technique improves robustness of the estimate (Buckland et al. 2001). All locations recorded on the printed maps were successively digitalized and the perpendicular distances from the transect calculated using the ARCVIEW extension "Distance Matrix 1.2".

In order to correctly apply Distance Sampling methods, four main assumptions should be satisfied (Buckland et al. 2001):

1. Transects should be randomly distributed with respect to the species' distribution.

2. All birds located on the transect should be detected.

3. Birds located near or on the transect should be detected before they are disturbed by the observer.

4. Distances should be measured accurately.

Taking into consideration this specific study, we observed that:

1. Transects were clearly not randomly distributed. Contrary to the recommendations of

Buckland et al. (2001), transects followed the urban road network, and thus did not represent a random sample of various habitats of the city. Moreover, each linear path was located on centres of roadways where pigeon density is obviously low, since the birds could be disturbed by road traffic. These conditions could lead to a significant underestimate of population density. It is important to note, however, that this are intrinsic, structural biases related to urban habitats, and thus it should affect all surveys similarly in the same season but in different years. To reduce the possible effects of this sampling problem, we left-truncated the data in order to exclude the low-density area near each transect (see below; Buckland et al. 2001).

2. The assumption that all birds on the transect are detected seems reasonable considering the open habitat (road centres) within which transects were laid.

3. The assumption that birds are not initially disturbed by the observer seems to be easily satisfied, since feral pigeons are habituated to humans and could be approached quite easily with practically no escape reactions.

4. Given the detailed maps at hand, the familiarity with the city of the observer and the relatively short distances of detections of feral pigeons (more than $50 \%$ of detections were within $15 \mathrm{~m}$ from transects), the assumption for accurate measurements seems to be met.

Distance data were transformed into 2-m intervals and analyzed using the software DISTANCE 5.0 (Thomas et al. 2005). We modelled the detection-probability function considering the clusters of individuals. Birds density estimation was then obtained by multiplying clusters density by mean cluster size, as preliminary inspections of the data did not indicate any size bias problem (Buckland et al. 2001). 
Given the current limitations of DISTANCE regarding analysis of nested design, we analyzed the data collected in the two periods separately. We hypothesized that in each period the shape of the detection function in the two strata was essentially the same, only differing in scale due the different density of buildings. We thus considered two different multiple covariates Distance Sampling models for the two periods, fitting a global model for the detection-probability function, and using stratum as a factor covariate. In each model, mean cluster size was estimated globally, since we have no reason to assume any difference between strata in the flocking behaviour of feral pigeons, while encounter rate (number of clusters per unit length of transect) was estimated by stratum.

Detection-probability function was a-priori modelled considering the following key functions:

1. Half-normal plus up to three cosine adjustment terms.

2. Hazard-rate plus up to three simple polynomials terms.

The best model was chosen using Akaike Information Criterion (AIC; Buckland et al. 2001; Burnham and Anderson 2002). We started with a model with no adjustments, and gradually added one term at a time in order to improve the fit of the model. These models were then used to calculate density only if $\chi^{2}$ goodness-of-fit test was not significant. We discarded all the observations beyond $38 \mathrm{~m}$ (January; $18 \%$ of distance data) and $42 \mathrm{~m}$ (November; $13 \%$ of distance data) in order to improve the fit of the curve and to avoid the smallest estimated probabilities of detection of clusters being below 0.2 (Thomas et al. 2005). Mean cluster size was calculated using the same truncation distances specified above.

Data were also left-truncated by excluding the first $4 \mathrm{~m}$ near the line. The width of this left truncation was chosen to represent width of the roads upon which transects were laid. Using ARCVIEW, we classified the half-width of each road segment to the nearest meter (excluding both pavements), and then calculated the median of distributions of these halfwidths, which was $4.5 \mathrm{~m}$ considering all the pooled transects (stratum $1=4 \mathrm{~m}$, stratum $2=$ $4.5 \mathrm{~m}$ ). The truncation band was then set to $4 \mathrm{~m}$, i.e., rounding down the median half-width in order to reduce the chance of overestimating pigeon density.

Given the aim of this paper and available sample size, we determined global density estimates and calculated bootstrap variances by means of 1000 replications. Comparisons among parameters involved in these estimates were performed by considering the $95 \%$ confidence interval (CI95\%), as suggested by Johnson (1999). Detectability in the two periods was compared by means of the effective strip half-width $(\mu)$, i.e., the distance for which the number of birds detected beyond $\mu$ and the number of birds missed within $\mu$ of the line are equal (Buckland et al. 2001).

40 sampling units $(250 \times 250 \mathrm{~m}$; about $24 \%$ of the total study area, see Senar 1996$)$ were allocated proportionally to each stratum (stratum 1 had 10 units, stratum 2 had 30 units; Fig. 1), and randomly placed using a grid superimposed over a map of the study area. Unit size was determined as a trade-off between the need of taking into account a reasonable number of units for reliable abundance estimations and large enough in place of not too small with respect to pigeon movements and distribution in order to avoid "border effects" or low precision due to a high number of zero counts (Thompson et al. 1998). In this case, a "border effect" could be ruled out because of the small perimeter/area ratio, while the unit size satisfied the criterion suggested by Williams et al. (2002) in that the proportion of units 
with reasonable probability of being empty is well below $50 \%$. In addition, sampling times, during which feral pigeons are moving less (see above), should have contributed to alleviate problems related to unit size.

As mentioned in the Introduction, we counted pigeons while walking along roads in the sampled units. Population mean and variance were then calculated using the package "Survey 3.6-2" (Lumley 2004) of the statistical software R 2.4.1 (R Development Core Team 2006), considering 1000 bootstrap replications. As stated by Williams et al. (2002), estimates based on less than 30 sampling units are generally biased (variance is underestimated) especially if they are based on clustered distributed populations. For this reason we estimated abundance only at global level. Following Johnson (1999), the results of the surveys were compared using CI95\%. According to Senar (1996), we corrected Quadrate Counts by 3.5 in order to obtain a rough figure of pigeons abundance (see Introduction),

Power analysis

The power of Distance Sampling and Quadrate Counts in detecting a negative trend of pigeons population was evaluated by estimating the Minimum Detectable Rate of Change (MDRC) given the precision of these two methods [Coefficient of Variation (CV)] using the software TREND 3.0 (Gerrodette 1987, 1991, 1993). Since we were lacking suitable pilot data from a multiyear study, our power calculations were based solely on within-year variations of abundance. According to Hatch (2003) this kind of procedure leads to overestimates of power. It should be noted, however that the relatively limited home range of pigeons (Johnston and Janiga 1995; Sol and Senar 1995; Rose et al. 2006 and references therein) and the stability of urban habitat should substantially reduce the inter-annual variation of counts and thus the likelihood of power overestimation. This low inter-annual variability is also confirmed by periodic censuses performed in a small number of European cities (e.g. Barcelona, Bratislava, Venice; see Johnston and Janiga 1995; Giunchi et al. 2007 and references therein). Given the high costs of pest control plans on feral pigeons (see e.g. Johnston and Janiga 1995; Zucconi et al. 2003), power estimation took into account a relatively short study period ( $6 \mathrm{yr}$ ). The parameters used in the calculations were:

2. $\beta=0.8$

3. Linear or exponential type of change 264

4. Negative rate of change 265

5. 1-tail tests for significance 266

6. constant $\mathrm{CV}$ (variance linearly related to the squared mean of abundance) 267

7. Number of sampling occasions: 6 (1 per year) 268

\section{Results}

Figure 2 reports the frequency distribution of perpendicular distances of clusters detected in the two strata. It is evident that the number of detections on or close to the transect line was rather low. Considering the general tameness of feral pigeons, it seems unlikely that this 


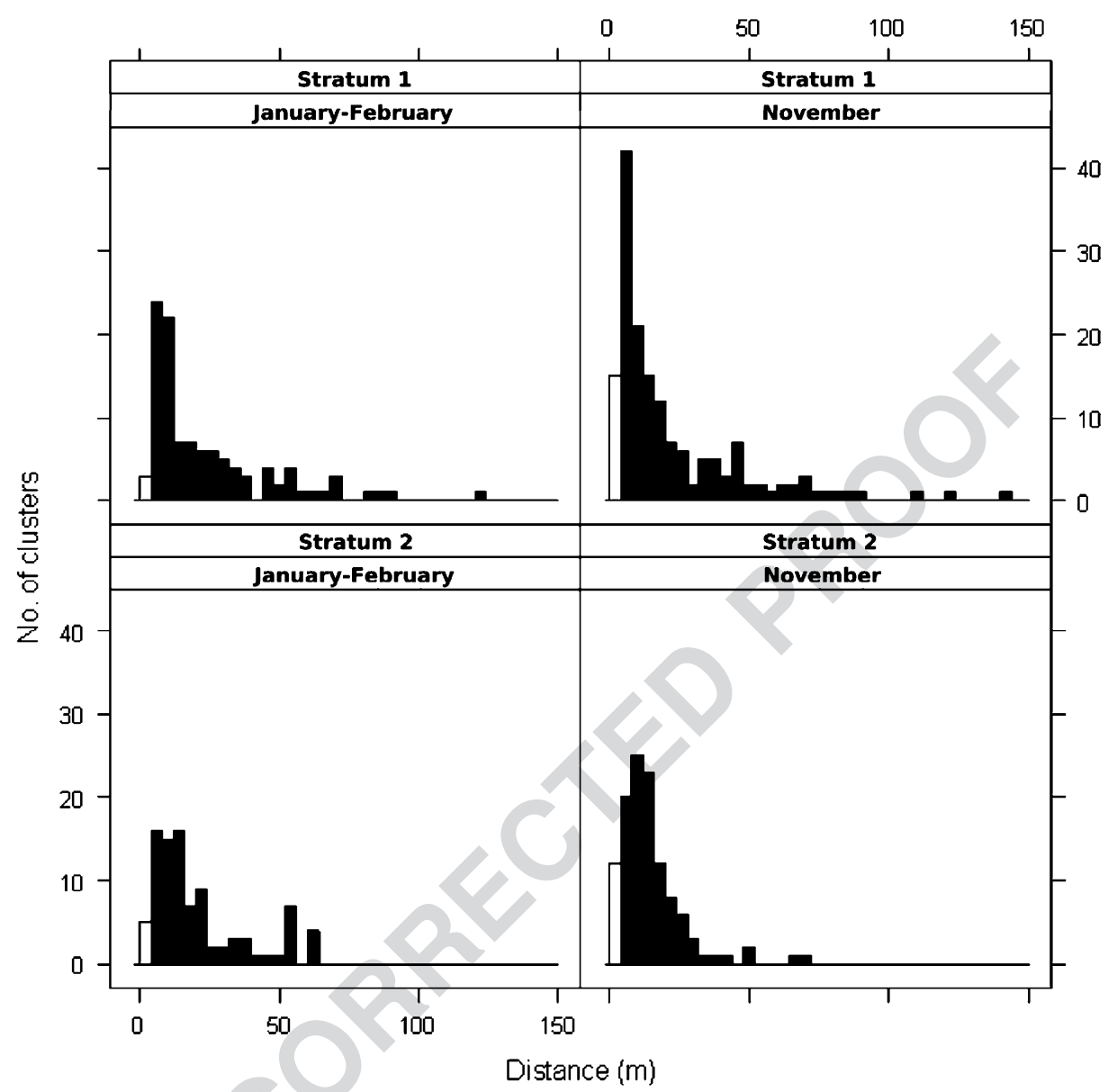

Fig. 2 Frequency distribution of perpendicular distances (bar width $=4 \mathrm{~m}$ ) of clusters detected in the two strata and in the two considered periods (January-February and November). Open bars indicate the lefttruncated interval

result was due to undetected evasive movements in response to the observer. While few detections near the transect line were expected, considering the non-random distribution of transects, these results support our choice to left truncate distance data (see Methods).

Table 1 reports the ranking of candidate models. In both surveys the hazard key with one simple polynomial adjustment term was selected for the detection function (Fig. 3). These models were characterized by $\mu=15.2 \mathrm{~m} \pm 1.0 \mathrm{SE}$ in January and by $\mu=10.3 \mathrm{~m} \pm 0.7$ in November with an acceptable fit in both surveys. It should be noted, however, that detection probability of November survey decreased quite rapidly near the line, producing a remarkably narrow shoulder of the detection function.

Summary statistics of parameters of the two models selected by minimum AIC are reported in Table 2. Encounter rate turned out to be substantially higher in stratum 1, which included the historic centre of the city, than in stratum 2 and it tended to increase from January to November. Mean cluster size was substantially comparable between the two periods, although there was a slight reduction in November. Given the remarkably spiked distribution of distance data, November estimates were less precise than January. 
Urban Ecosyst

Table 1 Ranking of candidate models used in Distance Sampling based on the difference in Akaike's information criterion (AIC)

\begin{tabular}{|c|c|c|c|c|c|c|}
\hline Period & Model $^{\mathrm{a}}$ & $K^{\mathrm{b}}$ & AIC & $\Delta \mathrm{AIC}^{\mathrm{c}}$ & $w_{i}^{e}$ & $\chi^{2}(P)^{\mathrm{e}}$ \\
\hline January-February & $\mathrm{HR}+1$ polynomial terms & 4 & 840.48 & 0.00 & 0.32 & 0.10 \\
\hline Right truncation $=38 \mathrm{~m}$ & $\mathrm{HN}+1$ cosine terms & 3 & 841.64 & 1.17 & 0.18 & 0.06 \\
\hline \multirow[t]{6}{*}{ Left truncation $=4 \mathrm{~m}$} & HR & 3 & 841.66 & 1.18 & 0.18 & 0.05 \\
\hline & $\mathrm{HN}+2$ cosine terms & 4 & 842.33 & 1.85 & 0.13 & 0.06 \\
\hline & $\mathrm{HR}+2$ polynomial terms & 5 & 842.67 & 2.20 & 0.11 & 0.06 \\
\hline & $\mathrm{HN}+3$ cosine terms & 5 & 844.33 & 3.85 & 0.05 & 0.04 \\
\hline & $\mathrm{HR}+3$ polynomial terms & 6 & 844.89 & 4.41 & 0.04 & 0.04 \\
\hline & $\mathrm{HN}$ & 2 & 847.26 & 6.78 & 0.01 & 0.01 \\
\hline November & $\mathrm{HR}+1$ polynomial terms & 4 & $1,192.85$ & 0.00 & 0.32 & 0.42 \\
\hline Right truncation $=42 \mathrm{~m}$ & $\mathrm{HN}+1$ cosine terms & 3 & $1,194.63$ & 1.79 & 0.13 & 0.38 \\
\hline \multirow[t]{6}{*}{ Left truncation $=4 \mathrm{~m}$} & $\mathrm{HR}+2$ polynomial terms & 5 & $1,194.65$ & 1.81 & 0.13 & 0.30 \\
\hline & $\mathrm{HN}+3$ cosine terms & 5 & $1,195.97$ & 3.12 & 0.07 & 0.40 \\
\hline & $\mathrm{HN}+2$ cosine terms & 4 & $1,196.61$ & 3.77 & 0.05 & 0.30 \\
\hline & $\mathrm{HR}+3$ polynomial terms & 6 & $1,196.83$ & 3.99 & 0.04 & 0.35 \\
\hline & HR & 3 & $1,203.79$ & 10.95 & 0.00 & 0.03 \\
\hline & $\mathrm{HN}$ & 2 & $1,205.55$ & 12.70 & 0.00 & 0.01 \\
\hline
\end{tabular}

All the parameters were computed by Distance

${ }^{\text {a }}$ The models tested were Half-Normal (HN) plus up to three cosine adjustment terms and Hazard-Rate (HR) plus up to three simple polynomials terms

${ }^{\mathrm{b}}$ Number of parameters

${ }^{\mathrm{c}}$ Difference in AIC from the best model

${ }^{\mathrm{d}}$ Model weights (see Burnham and Anderson 2002)

${ }^{\mathrm{e}} P$-value of the $\chi^{2}$ goodness of fit test

Nevertheless, pigeon density was considerably higher in November than in January, as expected.

As summarized in Table 3, population estimates obtained in the two surveys were quite different and both much lower than results from Distance Sampling (Fig. 4). Contrary to expectations, January abundance turned out to be substantially higher than November (663 birds $/ \mathrm{km}^{2}$ vs. 429 birds $/ \mathrm{km}^{2}$ ). The precision (CV) of these estimates decreased accordingly from January to November, but in both periods it was noticeably higher than that obtained using Distance Sampling (January: 0.14 vs. 0.17; November: 0.10 vs. 0.20). Using a correction factor=3.5 (see Methods), our results correspond to a population estimate of ca. 24000 in January, about double the Distance Sampling estimate of the same period, and ca. 15500 in November, perceptibly lower than Distance Sampling estimate.

Table 4 reports MDRC estimated using the software TRENDS. As expected, Quadrate 


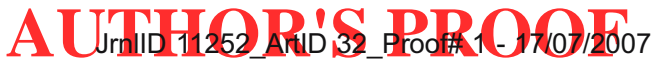

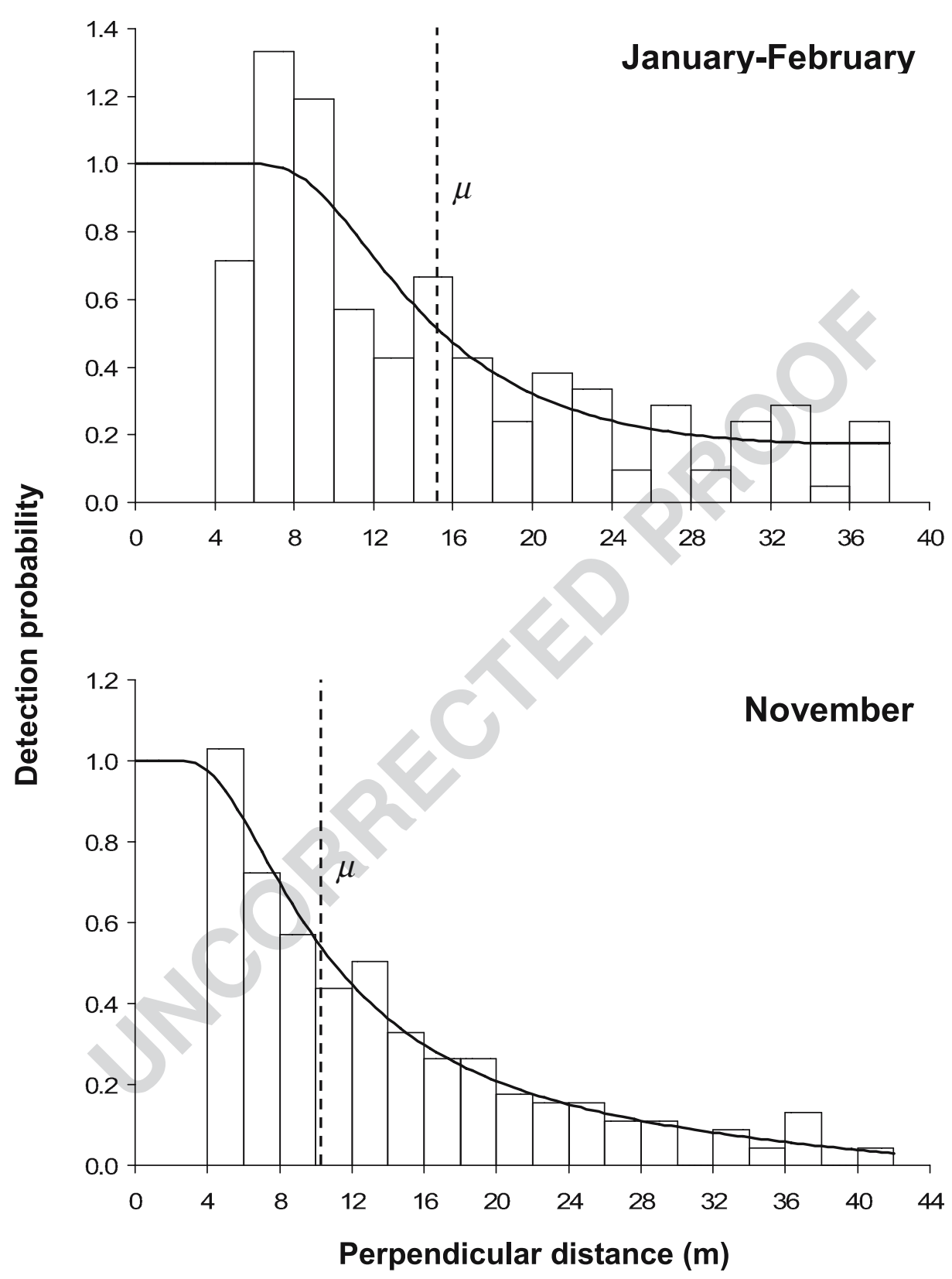

Fig. 3 Detection probability (continuous line) plot, histogram of perpendicular distances, and effective strip width $(\mu)$ for January-February and November surveys

January, while it substantially increased in November, when Quadrate Counts estimate was unexpectedly low. Overall, these results suggested that both methods were able to detect a noticeable negative trend in population size which corresponded roughly to a decrease of at least $10 \% \mathrm{yr}^{-1}$. 
Urban Ecosyst

Table 2 Encounter rate, cluster size, and density estimates obtained by Distance Sampling and computed from Distance ${ }^{\mathrm{a}}$

\begin{tabular}{|c|c|c|c|c|c|c|c|}
\hline Survey & Stratum & $\begin{array}{l}\text { No. of } \\
\text { clusters }\end{array}$ & $\begin{array}{l}\text { Encounter rate } \\
\text { (clusters } / \mathrm{km} \text { ) }\end{array}$ & $\begin{array}{l}\text { Mean } \\
\text { cluster size }\end{array}$ & Cluster $/ \mathrm{km}^{2}$ & Animals $/ \mathrm{km}^{2}$ & $\mathrm{CV}^{\mathrm{b}}$ \\
\hline \multirow[t]{2}{*}{$\begin{array}{l}\text { January- } \\
\text { February }\end{array}$} & 1 & 85 & $\begin{array}{l}31.0 \\
(21.5-44.8)\end{array}$ & \multirow[t]{2}{*}{$\begin{array}{l}2.8 \\
(2.3-3.3)\end{array}$} & \multirow[t]{2}{*}{$\begin{array}{l}497.2 \\
(391.4-704.9)\end{array}$} & \multirow[t]{2}{*}{$\begin{array}{l}1388.3 \\
(1137.0-1812.8)\end{array}$} & \multirow[t]{2}{*}{0.15} \\
\hline & 2 & 74 & $9.6(7.0-13.2)$ & & & & \\
\hline \multirow[t]{2}{*}{ November } & 1 & 126 & $\begin{array}{l}46.0 \\
(36.8-57.4)\end{array}$ & $\begin{array}{l}2.3 \\
(2.1-2.8)\end{array}$ & $\begin{array}{l}1081.0 \\
(691.5-1592.5)\end{array}$ & $\begin{array}{l}2471.5 \\
(1857.1-3364.3)\end{array}$ & \multirow[t]{2}{*}{0.21} \\
\hline & 2 & 108 & $\begin{array}{l}14.0 \\
(8.7-22.5)\end{array}$ & & & & \\
\hline
\end{tabular}

${ }^{\text {a }}$ CI $95 \%$ [2.5\% and 97.5\% quantiles of the bootstrap estimates $(R=1,000$ resamples)] are reported in parentheses

${ }^{\mathrm{b}} \mathrm{CV}$ refers to animal density

\section{Discussion}

Results obtained in this study suggest that Distance Sampling is a viable and efficient alternative to traditional methods used to estimate feral pigeon population size and to monitor population trends. Even though we did not perform a proper test of accuracy, Distance Sampling performed fairly well under our sampling conditions and it clearly outperformed Quadrate Counts. For instance, the trend of the two Distance Sampling estimates evidenced a clear increase of abundance from January to November, as predicted by considering demographic characteristics of feral pigeons populations (Johnston and Janiga 1995) and, in particular, the annual trend of breeding activity recorded in the nearby city of Lucca (Giunchi et al. 2007). On the other hand, it is hard to give a reasonable biological explanation of the consistent decrease of abundance indicated by Quadrate Counts in the second survey, which followed the main part of the breeding season of the population. On the contrary, it seems reasonable to hypothesize that pigeon detectability varied consistently across both census periods. As mentioned in the Introduction, the first survey was indeed carried out at the beginning of the breeding season with few active nests. In fact, most detections were of pigeons courting or searching for mates. These behaviours probably favoured detecting pigeons during the first hours after dawn and increased the fraction of population actually detected during the survey. On the other hand, in November the few breeding and courting pigeons were detected. In this period, most birds were relatively inactive since they began feeding later in the morning (see also Lefebvre and

Table 3 Summary statistics ( \pm bootstrap SE) of results of the Quadrate Counts analysis

\begin{tabular}{llllllll}
\hline Survey & Stratum & $\begin{array}{l}\text { Total } \\
\text { sampling } \\
\text { units }\end{array}$ & $\begin{array}{l}\text { Selected } \\
\text { sampling } \\
\text { units }\end{array}$ & Birds recorded & Birds/units & Abundance & $C V^{\text {a }}$ \\
\hline January-February & 1 & 42 & 10 & 973 & $41.5 \pm 5.6$ & $6841.8 \pm 932.0$ & 0.14 \\
\multirow{2}{*}{ November } & 2 & 123 & 30 & 672 & & & \\
& 1 & 42 & 10 & 679 & $26.8 \pm 2.7$ & $4426.2 \pm 438.2$ & 0.10 \\
& 2 & 123 & 30 & 384 & & & \\
\hline
\end{tabular}




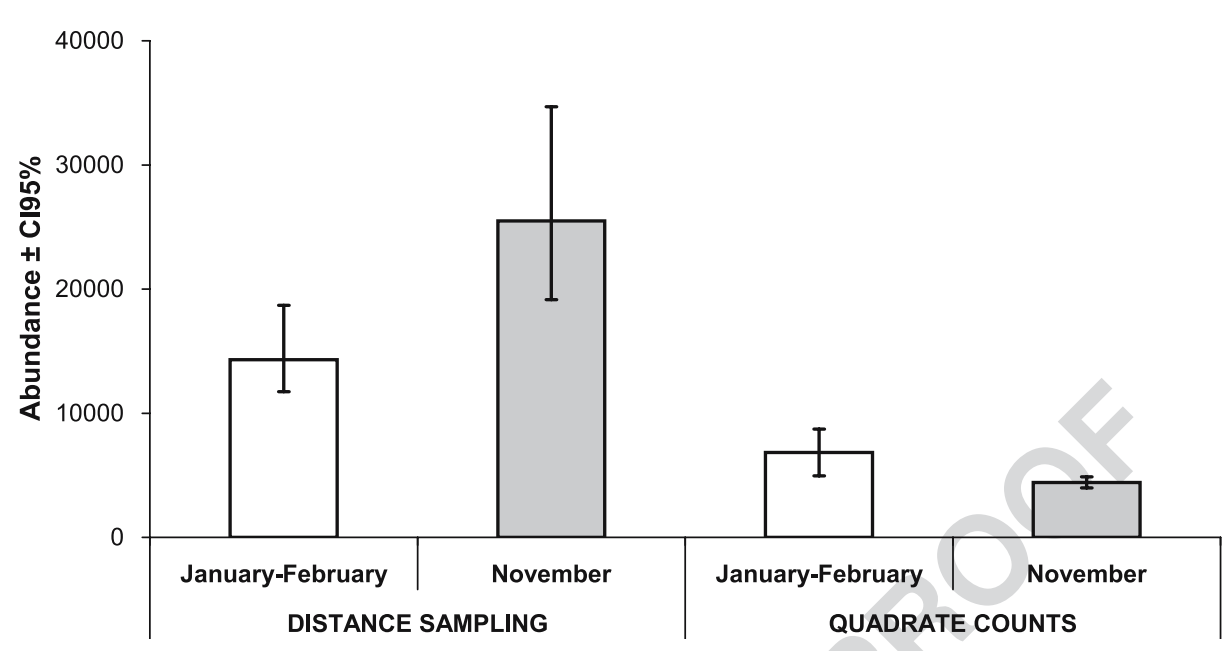

Fig. 4 Estimated abundances $[ \pm$ 95\% confidence intervals (CI 95\%)] obtained in Distance Sampling and Quadrate Counts analysis during the two surveys

Giraldeau 1984; Johnston and Janiga 1995; Soldatini et al. 2006). This change in behavior of pigeons likely decreased the fraction of birds detected in November. Interestingly, the hypothesis of a decreased detectability in November is also supported by the reduction of $\mu$ recorded in this survey. Given these considerations, it is evident that the use of "fixed" correction factor is of no help in correcting the intrinsic biases of Quadrate Counts estimates. Indeed, as stated by several authors (see e.g. Sutherland 1996), the use of correction factors derived under specific conditions in completely different contexts is best avoided, since it could lead to misleading results. Considering our specific case, it is clear that the fractions of birds detected in January and November are not the same, and, given the data at hand, there is no way to assess in which case the chosen correction factor is more appropriate, if it is. This further leads us to stress the need to estimate an appropriate correction factor each time Quadrate Counts method is used.

Given these considerations, it seems clear that the relatively high precision recorded for Quadrate Counts is substantially useless when trying to assess population trends of pigeons, given the biases of this method, and the problems of repeatability for any index of abundance (Sutherland 1996; Thompson et al. 1998; Schwarz and Seber 1999; Pollock et al. 2002; Rosenstock et al. 2002). It should be noted, moreover, that the use of case-specific correction

Table 4 Minimum detectable rate of change (MDRC) of feral pigeon populations estimated using Trends 3.0 (Gerrodette, 1987, 1991, 1993) and precision (CV) obtained by Distance Sampling and Quadrate Counts methods

\begin{tabular}{lllll}
\hline Survey & Method & CV & Type of trend & Annual MDRC \\
\hline January-February & Distance Sampling & 0.15 & Linear & -0.09 \\
& & & Exponential & -0.10 \\
& Quadrate Counts & 0.14 & Linear & -0.08 \\
& & & Exponential & -0.10 \\
November & Distance Sampling & \multirow{2}{*}{0.21} & Linear & -0.11 \\
& & & Exponential & -0.14 \\
& Quadrate Counts & 0.10 & Linear & -0.06 \\
& & & Exponential & -0.07 \\
\hline
\end{tabular}


factors, while likely improving the accuracy, should reduce the precision of Quadrate Counts, because variability of the estimate of correction factor has to be included in calculation of global variance. For instance, if we use the "Delta Method" (Burnham et al. 1987) to estimate the variance of corrected Quadrate Counts and if we assume a rather precise estimate of correction factor $(\mathrm{CV}=0.10)$, comparable to that reported in Senar and Sol (1991), we obtain two values of CV (January $=0.16$, November $=0.13$ ), which are not far from those recorded for Distance Sampling, at least in the first period (see Table 2). In terms of this last method, the precision of the two estimates is comparable with those recorded in other wildlife surveys (examples in Sutherland 1996; Thompson et al. 1998; Bibby et al. 2000; Buckland et al. 2001; Williams et al. 2002). Even though the above mentioned problems of overestimation should be born in mind (see Methods), the results of power analysis suggests that at least the precision recorded in January is probably enough for evaluating expected results of a pest control action, since published rates of decrease recorded in field studies or obtained in simulated analyses are usually higher than $10 \% \mathrm{yr}^{-1}$ (e.g. Haag 1995; see also Giunchi et al. 2007), at least during the first years of pest control. This power could be further increased by improving the precision of estimates by (1) accounting for variability among strata when allocating sampling units (Neyman allocation; see Thompson et al. 1998); (2) increasing the number of strata and/or by considering habitat covariates; and (3) increasing coverage. Regarding point (1), it should be noted that at least in the present case this technique should have significantly improved precision only in November, given the noticeably variability of encounter rate recorded only in this survey (encounter rate $C V$, January: Stratum $1=$ Stratum 2=0.16; November: Stratum $1=0.09$, Stratum 2=0.23). For what concern point (2), the presented data confirmed that the stratified design is particularly recommendable for feral pigeons survey, given the strong heterogeneity recorded among the two strata. It is likely that the incorporation of habitat variables (e.g. road density, buildings characteristics) into the survey design could further increase the precision by reducing habitat heterogeneity within strata, even though care should be taken in order to avoid over-stratifying the study area. While the two above mentioned improvements of the survey design are feasible both for Distance Sampling and Quadrate Counts since they do not significantly rise the survey costs, the increase of coverage seems particularly recommendable for Distance Sampling. Indeed, even though we did not perform a precise evaluation of their actual costs, it seems evident that the two methods did not imply any substantial difference both in observer effort of collecting data and in transfer time between sampling units, given the comparable number of units and their random distribution. We could assume, then, that the costs of Quadrate Counts and Distance Sampling should have been proportional to the total length of the roads walked during each survey. For Distance Sampling this length was equal to the total length of the transects, i.e., about $10 \mathrm{~km}$. Since Quadrate Counts is based on an intensive search of pigeons in each sampling unit, a minimum figure of the effort could be derived by considering the total length of all road segments within each cell, i.e. about $34 \mathrm{~km}$. This means that Distance Sampling estimates of population abundance were obtained with less than one-third of the effort employed for Quadrate Counts. Since the considered coverage of Quadrate Counts (about 24\% of the study area) should not be probably further reduced, in order to obtain reliable results (see Senar 1996), it seems evident that any unbiased Quadrate Counts estimate of feral pigeon population size, which provides for a contextual determination of a suitable correction factor, would need far more effort than those needed for a reasonably precise Distance Sampling estimate.

Obviously, Distance Sampling is not immune from drawbacks. Given the relatively short right truncation distance, we are confident that the use of mean cluster size instead of other 
techniques (e.g. size-biased regression; see Buckland et al. 2001) did not introduce any significant bias in our abundance estimation, even though we have to acknowledge the relevant variability of recorded flock size, especially evident in November, which significantly decreased the precision of the estimates. This result further stresses the opportunity of surveying feral pigeons abundance when their flocking behaviour is less extreme, i.e. before the beginning of the breeding season, and before pigeons form large aggregations near relevant food sources, i.e. early in the morning (see also Lefebvre and Giraldau 1984; Lefebvre 1985; Johnston and Janiga 1995). The main problem of Distance Sampling is however related to the non-random distribution of transects. Indeed, the strongly inhomogeneous accessibility of urban habitat prevented the use of any automatic procedure for designing the survey, such as the survey design component of DISTANCE. Instead, we were forced to adapt the randomly chosen transect to the urban road network, thus rendering the distribution of sampling units not truly random. As stated in the Methods, however, this sampling problem should be regarded as intrinsic of any urban ground-based birds count, and thus it could not be easily solved, except by using markrecapture/resight techniques, which are rather more costly and generally not well suited for counting birds in the urban habitat (Senar 1996). The solution here adopted to alleviate this problem - i.e. left truncation of distance data - was not devoid of defects. Indeed, since detectability at 0 distance was inferred on the basis of the frequency distribution of contacts recorded at distances not subjected to truncation, it is possible that it could have been overestimated, leading to an overestimated abundance (Buckland et al. 2001). Moreover, the use of the median road half-width could be considered not completely satisfying, given the substantial heterogeneity of the roads where the transects laid. Overall, the likelihood of this theoretical overestimation seems rather low, especially considering the figures obtained using the corrected version of Quadrate Counts, but clearly this topic deserve further investigation. It should be noted, however, that this eventual bias could be at least partially reduced under a long-term pest control protocol, by estimating pigeons' detectability at transect level and using different left-truncation distances depending on the actual width of the roads where each transect lays. This procedure needs at least $\geq 40$ contacts per transects in order to obtain reliable estimates (see Buckland et al. 2001), but, given the recorded encounter rate of feral pigeons, it seems likely that this threshold could be easily reached by pooling data collected during the same season over a relatively small number of years. A second problem, which clearly emerged from this study, was the spiked nature of distance data, which was mainly due to the high number of visual hindrances (caused mainly by high buildings), which determined an abrupt reduction of pigeon detectability even relatively close to the transects. November distance data, in particular, were particularly problematic, given the very narrow shoulder of the detection function. This type of frequency distribution of distances posed several problems when modelling distance data (Buckland et al. 2001), and, indeed, the fit of even the best models was not particularly high. It should be noted, however, that abundance estimates of the highest ranking candidate models (differing by AICs of 2 or fewer from the best model) were rather comparable (data not presented), thus indicating that model selection do not have a crucial effect on the presented results. Again, it seems likely that this problem could be at least partially solved under a long-term pest control program by pooling data collected in different years (see above), even though it seems reasonable to recommend to avoid counting pigeons at their annual population peak.

In the end, it is important to remark that the above-mentioned theoretical problems of accuracy of Distance Sampling should not have any relevant effect on its repeatability, given their dependence on the structural characteristics of the urban environment, which 
should be roughly the same in different years. This means that, contrary to Quadrate Counts, even a systematically biased Distance Sampling should be an unbiased tool for detecting population trends.

To conclude, our data suggest that Distance Sampling is an effective survey method for feral pigeons, and therefore it could be profitably used in population studies on these birds in urban environment. Moreover, this technique should be extremely useful as part of effective management programs, because it helps to rigorously assess both the costs for control, by providing a reasonable estimate of population size, and the effectiveness of eventual control actions, by objectively quantifying their actual effects on pigeons abundance.

Acknowledgments Thanks are due to Cecilia Soldatini and to Enrica Pollonara for their valuable comments on an earlier draft of this manuscript. We appreciate the improvements in English usage made by Peter Lowther through the Association of Field Ornithologists' program of editorial assistance.

\section{References}

Anderson DR (2003) Response to Engeman: index values rarely constitute reliable information. Wildl Soc Bull 31:288-291

Barbieri F, De Andreis C (1991) Indagine sulla presenza dei colombi (Columba livia forma domestica) nel centro storico di Pavia e nell'oltrepò pavese (U.S.L. N. 79, Voghera). Suppl Ric Biol Selvag 17:195-198

Bart J, Earnst S (2002) Double sampling to estimate density and population trends in birds. Auk 119:36-45

Bibby CJ, Burgess ND, Hill DA, Mustoe S (2000) Bird census techniques. Academic Press, London

Buckland ST, Anderson DR, Burnham KP, Laake JL, Borchers DL, Thomas L (2001) Introduction to distance sampling: estimating abundance of biological populations. Oxford University Press, New York

Buijs JA, Van Wijnen JH (2001) Survey of feral rock doves (Columba livia) in Amsterdam, a bird-human association. Urban Ecosyst 5:235-241

Burnham KP, Anderson DR (2002) Model selection and multimodel inference - a practical information-theoretic approach. Springer-Verlag, New York

Burnham KP, Anderson DR, White GC, Brownie C, Pollock KH (1987) Design and analysis methods for fish survival experiments based on release-recapture. American Fisheries Society, Bethesda, Maryland

Bursi E, Gelati A, Ferraresi M, Zannetti G (2001) Impiego della nicarbazina nel controllo della riproduzione del colombo randagio di città. Ann Fac Med Vet Parma 21:97-115

Cochran WG (1977) Sampling. John Wiley \& Sons, New York

Gerrodette T (1987) A power analysis for detecting trends. Ecology 68:1364-1372

Gerrodette T (1991) Models for power of detecting trends - a reply to Link and Hatfield. Ecology 72:1889-1892

Gerrodette T (1993) Trends: software for a power analysis of linear regression. Wildl Soc Bull 21:515-516

Giunchi D, Baldaccini NE, Sbragia G, Soldatini C (2007) On the use of pharmacological sterilisation to control feral pigeon populations. Wildl Res (in press)

Haag D (1990) Lebenserwartung und Altersstruktur der strassentaube Columba livia forma domestica. Ornithol Beob 87:147-151

Haag D (1991) Population density as a regulator of mortality among eggs and nestlings of feral pigeons (Columba livia domestica) in Basel, Switzerland. In: Pinowski J, Kavanagh BP, Górski W (eds) Nestling mortality of granivorous birds due to microorganisms and toxic substances. PWN-Polish Scientific Publishers, Warsaw, pp. 21-31

Haag D (1995) Regulation of the street pigeon in Basel. Wildl Soc Bull 23: 256-260

Hatch SA (2003) Statistical power for detecting trends with applications to seabird monitoring. Biol Conserv 111:317-329

Johnson DH (1999) The insignificance of statistical significance testing. J Wildl Manage 63:763-772

Johnston RF, Janiga M (1995) The feral pigeons. Oxford University Press, London

Jokimäki J, Suhonen J (1998) Distribution and habitat selection on wintering birds in urban environments. Landsc Urban Plan 39:253-263

Lefebvre L (1985) Stability of flock composition in urban pigeons. Auk 102:886-888

Lefebvre L, Giraldeau LA (1984) Daily feeding site use of urban pigeons. Can J Zool 62:1425-1428 
Marzluff JM, McGowan KJ, Donnelly R, Knight RL (2001). Causes and consequences of expanding American crow populations. In: Marzluff JM, Bowman R, Donelly R (eds) Avian ecology and conservation in an urbanizing world. Kluwer Academic Press, Norwell, MA, pp. 332-363

Lumley T (2004) Analysis of complex survey samples. J Stat Softw 9:1-19

Pollock KH, Nichols JD, Simons TR, Farnsworth GL, Bailey LL, Sauer JR (2002) Large scale wildlife monitoring studies: statistical methods for design and analysis. Environmetrics 13:105-119

R Development Core Team (2006) R: a language and environment for statistical computing. R Foundation for Statistical Computing, Vienna, Austria

Rose E, Nagel P, Haag-Wackernagel D (2006) Spatio-temporal use of the urban habitat by feral pigeons (Columba livia). Behav Ecol Sociobiol 60:1-13

Rosenstock SS, Anderson DR, Giesen KM, Leukering T, Carter MF (2002). Landbird counting techniques: current practices and an alternative. Auk 119:46-53

Sacchi R, Gentilli A, Razzetti E, Barbieri F (2002) Effects of building features on density and flock distribution of feral pigeons Columba livia var. domestica in an urban environment. Can J Zool 80:48-54

Schwarz CJ, Seber AF (1999) A review of estimating animal abundance III. Stat Sci 14:427-456

Senar JC (1996) Bird census techniques for the urban habitat: A review. In: Alleva E, Baldaccini NE, Fortuna P, Mantovani A (eds) Controllo delle popolazioni ornitiche sinantropiche: problemi e prospettive. Istituto Superiore di Sanità, Roma, pp. 36-44

Senar JC, Sol D (1991) Censo de palomas Columba livia var. de la ciudad de Barcelona: aplicaciòn del muestreo estratificado con factor de correcciòn. Butlleti del Grup Catala d'Anellament 8:19-24

Soldatini C, Mainardi D, Baldaccini NE, Giunchi D (2006) A temporal analysis of the foraging flights of feral pigeons (Columba livia f. domestica) from three Italian cities. Ital J Zool 73:83-92

Sutherland WJ (1996) Ecological census techniques: a handbook. Cambridge University Press, Cambridge

Thomas L, Laake JL, Strindberg S, Marques FFC, Buckland ST, Borchers DL, Anderson DR, Burnham KP, Hedley SL, Pollard JH, Bishop JRB, Marques TA (2005) Distance 5.0. Research unit for wildlife population assessment. University of St. Andrews, UK

Thompson WL (2002) Towards reliable bird surveys: Accounting for individuals present but not detected. Auk 119:18-25

Thompson WL, White GC, Gowan C (1998) Monitoring vertebrate populations. Academic Press, London

Uribe F, Colom L, Camerino M, Ruiz J, Senar JC (1984) Censo de las palomas semidomésticas (Columba livia var.) de la ciudad de Barcelona. Misc Zool 8:237-244

Williams BK, Nichols JD, Conroy MJ (2002) Analysis and management of animal populations. Academic Press, San Diego

Zucconi S, Galavotti S, Deserti R (2003) I colombi in ambiente urbano- Sintesi del progetto di ricerca Nomisma. Disinfestazione Novembre/Dicembre 2003:9-21 


\section{AUTHOR QUERIES}

\section{AUTHOR PLEASE ANSWER ALL QUERIES.}

Q1. Sol and Senar 1995 is cited in the body but is not found in the reference list. Please provide references or else delete it from the body.

Q2. Please provide update on the publication status of Giunchi et al., 2007 if already available.

Q3. Is the reference by Zucconi et al. 2003 a journal? Please check. 